\title{
Strategies to Improve Hazardous Waste Management at the Faculty of Engineering Vitoria-Gasteiz UPV/EHU
}

\author{
By Ainara Saralegi ${ }^{1}$, Naiara Rojo ${ }^{1}$, Jon Alvarez ${ }^{1}$, Loli Encinas ${ }^{1}$, Josune Amurrio ${ }^{1}$
}

\begin{abstract}
Universities, considered as agents of social change, are essential for providing knowledge, innovations and solutions to the community, in order to nurture future leaders towards sustainable development. Therefore, universities are uniquely positioned to assist with implementing the 17 Sustainable Development Goals (SDG) and 169 targets to promote economic prosperity, social inclusion and environmental sustainability. In this context, the University of the Basque Country (UPV/EHU), with the initiative Campus Bizia Lab Programme (CBL), sees the SDG as a route map to bring the work of the university community (academic staff, service and administrative staff, and students) into line the major challenges facing the planet and people. As the production of hazardous waste (HW) has grown exponentially in recent years at the UPV/EHU, becoming an environmental problem of our time, the objective of this work, which is within the CBL, is to analyse the current HW management system at the Faculty of Engineering Vitoria-Gasteiz UPV/EHU and to develop strategies to minimize them and reduce the costs associated with their management. To this end, the data collected over the period 2013-2018 have been analyzed and different strategies have been proposed according to the 28 good practices stablished by the UPV/EHU.
\end{abstract}

Keywords: Environment, Sustainability, Sustainability Development Goals, University Community, Hazardous Waste

\section{Introduction}

Over the course of the last decades, human habits have been conditioning the normal functioning of life on the planet. Aspects such as the increase of the world population, the industrial advance and the uncontrolled exploitation of natural resources to satisfy a lifestyle based on single use items, have resulted in the inability of the planet to assimilate the rhythm of change that humanity is inducing (Huang \& Rust, 2011). In 2017, the worldwide material consumption reached 92.1 billion tons, up from 87 billion in 2015 and a 254 per cent increase from 27 billion in 1970, with the rate of resource extraction accelerating exponentially every year since (United Nations. Economic and Social Council, 2019). This clearly reflects the increased demand for natural resources, resulting in undue burden on environmental resources. Without urgent and concerted political actions, the global resource extraction could grow to 190 billion tons by 2060 (United Nations. Economic and Social Council, 2019).

The exponential increase in the use of natural resources and single use items, together with the lack of an adequate management system, leads to an uncontrollable increase of waste production, culminating in an unsustainable global situation (Ferronato \& Torretta, 2019). Therefore, nowadays, everything that concerns waste has acquired great importance. The 
consequences of an enormous generation of waste are no longer mere predictions, but a devastating and tangible reality. Thereby, most of the soils that sustain crops are contaminated, seas and oceans have become a landfill where the accumulation of waste is such that it has created what is called "plastic continent" or "waste island", underwater flora is disappearing, and the marine fauna has included the decomposition residues to its diet, either by necessity or confusion (Kallen, 2017).

Among different waste types, hazardous wastes (HWs) are receiving increasing attention, because the low concentration at which they can be considered harmful, as well as the environmental persistence or bioaccumulation that they present (the tendency that the residues have to remain in the environment thanks to their resistance to chemical or biological degradation), increases the problems related to HW generation and management (Augustsson, Sörme, Karlsson, \& Amneklev, 2017; Cousins, Ng, Wang, \& Scheringer, 2019). In this way, some organochloride compounds and heavy metals (lead, cadmium and mercury), for example, residues that have a long average life, constitute a serious risk for health and the environment. Although this type of wastes can be found naturally in the environment, their excessive production and subsequent accumulation is due to the manipulation of these materials in industrial processes (Brusseau, Pepper, \& Gerba, 2019). In recent decades, owing to the increasing amount of $\mathrm{HW}$ generated over the world, considerable efforts have been made to prevent the environmental and health problems associated with HWs, promoting mainly a sustainable development. Moreover, environmental policies have been hardened to promote a drastic transformation on a global scale in terms of HW generation and management (Carballo-Penela \& CastrománDiz, 2015). However, to make the sustainable development a reality, it is necessary to involve people from different sectors and levels of society. In this context, the United Nations (UN), as an intergovernmental organization that aims to maintain international peace and security, develop friendly relations among nations, achieve international cooperation, and be a center for harmonizing the actions of nations, presented an agreement in 2015, 'Transforming our world: the 2030 Agenda for sustainable development' (United Nations Division for Sustainable Development, 2015), which is one of the most ambitious and transcendental global agreements presented in recent history to promote sustainable development. The Agenda, with the 17 sustainable development goals (SDGs) as the central axis, is a guide to address the most pressing global challenges: ending poverty and promoting economic prosperity, social inclusion, environmental sustainability, peace and good governance for all peoples by 2030.

To obtain the desired sustainable development, there are changes that must occur both in the lifestyles and development, and in the styles of thought and knowledge. All these changes would only be possible on the basis of an education that promotes the responsibility and social conscience of all citizens, as well as the necessary training so that people can make decisions that favor the quality of life and sustainability (O'Flaherty \& Liddy, 2018). In this process, the role of universities (from its three fundamental functions: teaching, research and innovation) is crucial as responsible agents for training people in social leadership. The Agenda for sustainable development, which has its sights set on 2030, has the support of universities as relevant actors to create a culture in social responsibility in order to contribute transforming society (Leal Filho et al., 2019; ZamoraPolo \& Sánchez-Martín, 2019). Thereby, universities, propitiating new projects that 
address the challenges of the Agenda 2030 and incorporating competencies such as sustainability, responsibility and social commitment in their teaching, are essential agents on the way to transform society towards the sustainable development.

The University of the Basque Country (UPV/EHU), like other universities, has found in the Agenda 2030 a roadmap to align the work of the UPV/EHU with the great challenges of the planet regarding sustainable development. Thus, the UPV/EHU, as participant in the Erasmus project University Educators for Sustainable Development, promotes an initiative called Campus Biria Lab (CBL), in order to trigger a collaborative process among teachers, service and administrative staff, and students (transdisciplinary approach) to respond to sustainability challenges within the UPV/EHU itself. Furthermore, the CBL program is aligned with the priority lines of the EHUagenda 2030 (Universidad del País Vasco, UPV/EHU, 2019) for sustainable development (2019-2025), including the contribution of the UPV/EHU to 12 of the 17 SDGs of the Agenda 2030.

In the present work, the results obtained within the project 'ACTION-REDUCTION. Reinvent the classic laws for a more sustainable future of our Campus: actions to reduce consumption and waste', which is financially supported by the CBL program, will be presented. One of the objectives of this project has been to advance in the minimization of HW generation and optimize their management at the Faculty of Engineering of Vitoria-Gasteiz (FEVG) at the UPV/EHU. For this purpose, the current data collection system for HW of the FEVG has been reviewed, improving the observed weaknesses, and the data collected over the period 2013-2018 have been analyzed and different strategies have been proposed according to the 28 good practices stablished by the UPV/EHU (Dirección de sostenibilidad, 2018).

\section{Legal Frameworks in Hazardous Waste Management}

The classification into hazardous and non-hazardous waste is based on the system used for the classification and labelling of dangerous substances and preparations, which ensures the application of similar principles over the whole life cycle of materials. The properties that render waste hazardous are laid down in Annex III of Directive 2008/98/EC and are further specified by the Decision 2000/532/EC establishing a List of Waste, as last amended by Decision 2014/955/EU. Mainly, HW is any waste, or mixture of waste, which presents risk for public health or adverse effects for the environment. This risk or adverse effect may be due, regardless of its physical condition, to its toxicity, flammability, explosivity, reactivity or corrosivity. If a residue has one or more of these characteristics, it must be classified as hazardous waste. Moreover, Regulation 1272/2008 regulates the classification, labelling and packaging of HWs.

The determination of the dangerousness of unknown composition residues is carried out through the test methods described in Regulation 2008/440/EC. However, some waste discharges can be found outside the scope of application of the just cited legislations as they are regulated by own regimens, such as wastewater (regulated by wastewater legislation), the emission of industrial gases (governed by the emission control legislation), or radioactive waste, which are ordered according to the radioactivity legislation.

Finally, the substances classified as carcinogens are collected separately and any manipulation that involves them is regulated by Directive 2019/13/EC on the protection 
of workers against the risks related to exposure to carcinogens or mutagens at work.

\section{Methodology}

The FEVG at the UPV/EHU, is a center focused on teaching and research activities, especially in the field of engineering, and currently has 105 academic staff, 23 service and administrative staff, and 850 students, approximately. The Faculty has several laboratories for the study of electricity and electronics, for the application of mechanical studies, chemical, thermal and hydraulic analysis, tests with materials, and in short, for the application of the theoretical concepts that are taught in their degrees and complementary courses. The generation of HW is mostly associated with the Department of Chemical and Environmental Engineering and the Motostudent initiative (annual initiative that consists of developing a motorcycle and due to which a certain volume of used oils is generated as $\mathrm{HW}$ ), which generate residues that cannot be managed with the rest of household waste, and must be considered as HW.

The Faculty intends to take control of the HW generated in order to comply with the regulations established by the UPV/EHU and verify the effectiveness of the actions undertaken in the area of waste management. Therefore, in this work, on one hand, the protocols used for HW data collection and quantification have been reviewed and optimized. Moreover, on the other hand, the data collected over the period 2013-2018 related to HW have been analyzed, as well as the expenditure that implies their management. Finally, different strategies have been proposed according to the 28 good practices stablished by the UPV/EHU, in order to improve HW management at the FEVG.

\section{Results and Discussion}

The classification of the HWs generated in the departments and laboratories of the FEVG is carried out in common agreement with the authorized external management company hired by the UPV/EHU, which is SITA SPE IBÉRICA, and following the good practice guide 'NTP 480: Hazardous waste management in the university and research laboratories'. In this way, the physicochemical properties of the wastes, the possible reactions of incompatibility in case of mixing and their final treatment are taken into account in order to group HWs into large sets. Considering all this aspects and the HWs generated at the FEVG, Table 1 presents the classification used at the FEVG for HWs. 
Table 1. HW classification used at the FEVG.

\begin{tabular}{|l|}
\hline HAZARDOUS WASTE \\
\hline LABORATORY REAGENTS \\
\hline LIQUID WASTES \\
\hline - Halogenated solvents \\
- Non-halogenated solvents \\
- Acid inorganic solutions \\
- Solutions with heavy metals \\
- Alkaline inorganic solutions \\
- Other organic liquids \\
- Oils \\
\hline CONTAINERS \\
\hline - Empty plastic containers $(<50 \mathrm{~L})$ \\
- Empty metallic containers $(<50 \mathrm{~L})$ \\
- Empty/broken glass containers \\
\hline OTHER WASTES \\
\hline - Absorbents and filter materials \\
\hline
\end{tabular}

Following the protocol used for HW data collection and quantification at the FEVG, as shown in Figure 1, correctly classified and segregated HWs are labeled according to Regulation 1272/2008, as mentioned before in section 2, and are packed in homologated containers. At this stage, it is necessary to take into account the expected final volume of the residue for a given period and adapt the size of the container to it, taking into account that containers cannot be filled more than $80 \%$. From the moment they are generated until they are collected by the management company for their treatment, HWs are stored in an adequate storage place (without exposure to sunlight, properly ventilated, etc.).

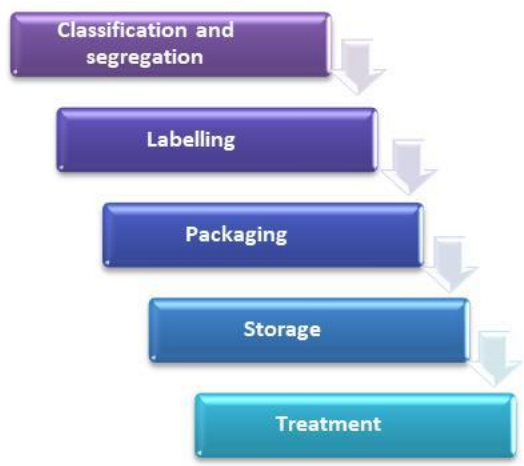

Figure 1. HW management procedure at the FEVG.

The HWs collected in the FEVG are first taken to the control center that the authorized external management company has, where they are weight and where an analytical first control is carried out to classify them according to their nature and the final treatment. Then, HWs are reconditioned and prepared to forward to the corresponding treatment 
plants for recycling, valorization, disposal, incineration or deposit under safety conditions. Finally, the management company publishes an annual report presenting the type and amount of treated HWs, as well as the costs associated with their treatment and management.

Reviewing the data collected at the FEVG and comparing with the data provided by SITA SPE IBÉRICA, some deviations have been found. On one hand, it has been observed that the data related to HWs is not weighed properly at the FEVG, just providing an approximate value. Therefore, within ACTION-REDUCTION project, the use of a balance (WILDCAT, Mettler Toledo, range $20 \mathrm{~g}-150 \mathrm{~kg}$ ) and the implantation of a spreadsheet where data such as date, mass, type of waste and observations must be noted, are proposed.

On the other hand, it has been observed that SITA SPE IBÉRICA treated some HWs classified at the FEVG as non-halogenated solvents, as halogenated solvents. This is because the management company analyzes de HWs before treating them, and if they contain more than $1 \%$ of halogenates, even if they are classified as non-halogenated by the FEVG, they are considered and treated as halogenated solvents. This fact is really important, since the cost related to the management of each type of waste (Table 2) is very different. Something similar happens with laboratory reagents. The management cost of laboratory reagents $(€ / \mathrm{t})$ is really high, and sometimes, laboratory residues like organic and inorganic solids are treated as laboratory reagents, due to deviations in management. Therefore, a greater control of the actions that generate HWs like halogenated solvents is proposed, so as not to mix them with non-halogenated solvents, as well as the incorporation of two new families to the list of the classification of HWs, organic solids and inorganic solids.

Table 2. Management costs of the HWs generated at the UPV/EHU.

\begin{tabular}{lc}
\hline TYPE OF WASTE & MANAGEMENT COST $(\boldsymbol{€} / \mathbf{t})$ \\
\hline Absorbents and filter materials & 350 \\
Acid inorganic solutions & 550 \\
Alkaline inorganic solutions & 550 \\
Empty/broken glass containers & 350 \\
Empty metallic containers (<50L) & 290 \\
Empty plastic containers (<50L) & 290 \\
Halogenated solvents & 850 \\
Laboratory reagents & 1.850 \\
Mercury & 3.500 \\
Non-halogenated solvents & 160 \\
Oils & 0 \\
Other organic liquids & 650 \\
Solutions with heavy metals & 650 \\
\hline
\end{tabular}

Regarding the data collected over the period 2013-2018 (Figure 2), it has been observed that the composition of the HW produced at the FEVG has changed throughout the evaluated years. As every year the activities carried out at the Faculty change, the same happens with the composition of the generated HW. On one hand, the teaching activity varies according to the laboratory practices proposed by each professor, affecting on the 
generated HW composition. On the other hand, as the research activity varies depending on the active projects that each department is working on, the HW composition varies from year to year. Therefore, the changes observed in the composition of the HW generated at the FEVG would be associated with a normal dynamic of the Faculty. Moreover, over years, an enormous effort has been made to raise awareness among laboratory users and to carry out their activities avoiding the wastage and mismanagement of resources, suggesting that the data presented in Figure 2 falls within normal ranges.

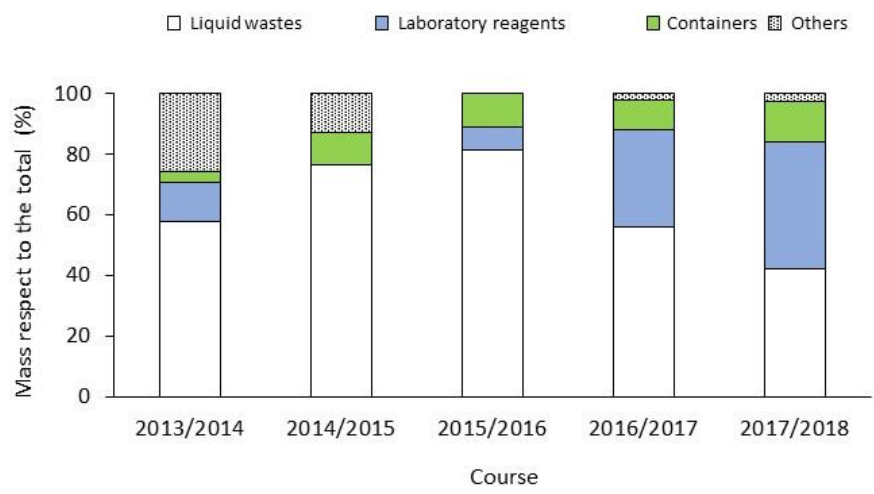

Figure 2. Composition respect to the total mass of HWs at the FEVG over the period 2013/2018.

As it is known, the management of all kinds of waste involves an economic expense. The expenses derived from the HW management generated in the FEVG are assumed by the $\mathrm{UPV} / \mathrm{EHU}$, as it is a center dependent on it. As mentioned previously, the external management company, SITA SPE IBÉRICA, publishes an annual report with the data type and amount of treated HWs, as well as the costs associated with their treatment and management. Figure 3 shows the cost associated with HW at the FEVG over the period $2013 / 2018$, presenting the total cost, as well as the management, material (the cost related to the material needed to storage properly the HW before being transported) and transport costs.

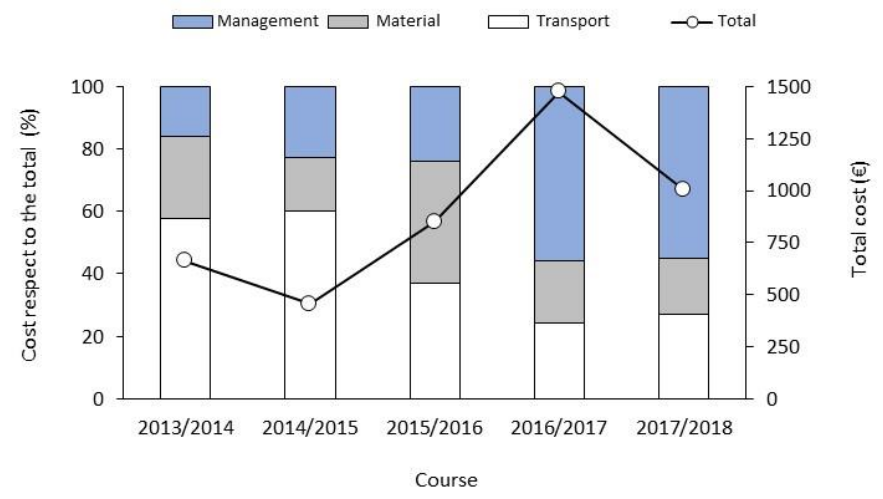

Figure 3. Cost associated with HW at the FEVG over the period 2013/2018.

The total cost associated with HW management, material and transport, increased 
significantly in the academic year 2016/2017, being almost 2 times higher than that registered in the previous academic year (2015/2016). This increase is mainly due to an increase in the expense associated with management. A large number of laboratory reagents was generated during 2016/207, associated with a cleanup and removal of expired reagents carried out in the Department of Chemical and Environmental Engineering. Thereby, in view of the high cost related to laboratory reagents management, $1.850 € / \mathrm{t}$ ( Table 2), the increase in the total cost would be justified.

Analyzing the costs related to transport, as observed in Figure 3, this expense has represented a highly variable percentage of the total spending, being $60 \%$ in the academic year 2014/2015 and 24\% in 2016/2017. These variations are because the costs associated with other items have increased, the case of management in the 2016/2017 and 2017/2018 courses, as an example. In addition, until summer 2015, the cost of transport was $95 € / \mathrm{h}$, and thereafter dropped to $90 € / \mathrm{h}$.

Finally, because of the hazardous nature of this type of reagents, either for the environment or for human health, the Department of Sustainability of the UPV/EHU, in collaboration with the Basque Government, analyzed the potential of the UPV/EHU to minimize the amount and management costs of HWs. Thus, 28 actions were identified in the 'Manual of good practices for the minimization of chemical wastes', which aims to improve compliance with European regulations. The manual distinguishes two major groups of actions, on one hand those dedicated to reduce HW generation, and on the other hand those dedicated to minimize the costs associated with HW management. Table 3 shows the assessment carried out within ACTION-REDUCTION project about the implementation of the good practices, as well as the practices that are currently taking place at the FEVG. Once this assessment has been made, the next step will be to implement the good practices identified as viable that are still not carrying out at the FEVG.

Table 3. Assessment of the implementation of the good practices at the FEVG.

\begin{tabular}{|l|l|c|c|}
\hline Context & Good practice & Viability & Applying \\
\hline \multirow{5}{*}{$\begin{array}{l}\text { Minimization of generation of } \\
\text { expired or unnecessary } \\
\text { product }\end{array}$} & $\begin{array}{l}\text { 1. Centralization or joint purchase to optimize the } \\
\text { acquisition of raw materials }\end{array}$ & Viable & Yes \\
\cline { 2 - 4 } & $\begin{array}{l}\text { 2. Raw material exchange system between } \\
\text { TRUKE application }\end{array}$ & Viable & No \\
\hline & $\begin{array}{l}\text { 3. Periodic inventories } \\
\text { 4. Incorporation of variables such as expiration and } \\
\text { degree of need in the materials purchase criteria }\end{array}$ & Viable & No \\
\hline \multirow{5}{*}{$\begin{array}{l}\text { Minimization of the } \\
\text { generation of raw material } \\
\text { packaging }\end{array}$} & $\begin{array}{l}\text { 5. Agreements with suppliers for the return of } \\
\text { packaging for reuse }\end{array}$ & $\begin{array}{c}\text { Not } \\
\text { viable }\end{array}$ & No \\
\hline $\begin{array}{l}\text { 6. Selection of products whose packaging can be } \\
\text { returned to the supplier }\end{array}$ & $\begin{array}{c}\text { Not } \\
\text { viable }\end{array}$ & No \\
\hline $\begin{array}{l}\text { 7. Selection of packaging products with the largest } \\
\text { size and least possible weight }\end{array}$ & Viable & Yes \\
\hline $\begin{array}{l}\text { 8. Self-management of packaging for reuse as } \\
\text { waste packaging }\end{array}$ & Viable & Yes \\
\hline Minimization of consumption & 9. Establishment of procedures that consider & Viable & Yes \\
\hline
\end{tabular}




\begin{tabular}{|c|c|c|c|}
\hline Context & Good practice & Viability & Applying \\
\hline \multirow[t]{5}{*}{ of raw materials } & $\begin{array}{l}\text { good environmental practices and the } \\
\text { improvement of the design and scale of the } \\
\text { experiments }\end{array}$ & & \\
\hline & $\begin{array}{l}\text { 10. Establishment of procedures to determine } \\
\text { when a mixture should be considered waste }\end{array}$ & Viable & No \\
\hline & 11. Solvent distillation for reuse & Viable & Yes \\
\hline & 12. Reuse of residual currents in other practices & Viable & No \\
\hline & $\begin{array}{l}\text { 13. Consideration of waste minimization in the } \\
\text { acquisition of equipment and instruments for } \\
\text { laboratories }\end{array}$ & Viable & Yes \\
\hline \multirow{3}{*}{$\begin{array}{l}\text { Minimization of } H W \\
\text { generation }\end{array}$} & $\begin{array}{l}\text { 14. Selection of minimally hazardous raw } \\
\text { materials }\end{array}$ & Viable & Yes \\
\hline & 15. On-site treatment of waste & $\begin{array}{l}\text { Not } \\
\text { viable }\end{array}$ & No \\
\hline & 16. Minimizing the consumption of absorbents & Viable & Yes \\
\hline \multirow{6}{*}{ Awareness } & $\begin{array}{l}\text { 17. Communication to teaching and research } \\
\text { units of the amount of waste generated and the } \\
\text { associated costs }\end{array}$ & Viable & No \\
\hline & $\begin{array}{l}\text { 18. Memory of generation and minimization of } \\
\text { HW }\end{array}$ & Viable & No \\
\hline & $\begin{array}{l}\text { 19. Public recognition of teaching and research } \\
\text { units that achieve effective waste reduction }\end{array}$ & $\begin{array}{l}\text { Not } \\
\text { viable }\end{array}$ & No \\
\hline & $\begin{array}{l}\text { 20. Awareness to the people responsible for the } \\
\text { laboratory and those responsible for waste } \\
\text { management }\end{array}$ & Viable & Yes \\
\hline & 21. Formation of work groups in each center & Viable & No \\
\hline & 22. Creation of a specific section on the website & Viable & No \\
\hline \multirow{2}{*}{$\begin{array}{l}\text { Minimization of costs } \\
\text { associated with management }\end{array}$} & $\begin{array}{l}\text { 23. Specific procedure for the use and } \\
\text { management of waste with a higher unit } \\
\text { management cost. }\end{array}$ & Viable & Yes \\
\hline & $\begin{array}{l}\text { 24. Selection of materials whose waste represents } \\
\text { lower cost }\end{array}$ & Viable & No \\
\hline \multirow{2}{*}{$\begin{array}{l}\text { Minimization of costs } \\
\text { associated with consumables }\end{array}$} & $\begin{array}{l}\text { 25. Selection of packaging for waste of the largest } \\
\text { size and lowest possible cost }\end{array}$ & Viable & Yes \\
\hline & 26. Filling of residual containers before delivery & Viable & Yes \\
\hline \multirow{2}{*}{$\begin{array}{l}\text { Minimization of costs } \\
\text { associated with the collection } \\
\text { and transport of } H W\end{array}$} & $\begin{array}{l}\text { 27. Minimization of the number of collections } \\
\text { required }\end{array}$ & $\begin{array}{l}\text { Not } \\
\text { viable }\end{array}$ & No \\
\hline & $\begin{array}{l}\text { 28. Minimization of collection times by the } \\
\text { manager }\end{array}$ & Viable & Yes \\
\hline
\end{tabular}

\section{Conclusions}

The exponential increase of HW production and the increasingly restrictive regulations in the field of HW management, concerns all over the world. It might seem that the FEVG, in relation to the total generation of waste and its corresponding management, constitutes a minimal part, and therefore its influence on an international scenario, is practically negligible. However, this work aims to show the relevance of each 
small entity in order to reduce HW amount and the costs related to their management. Moreover, the FEVG, as a higher education center, has an important role promoting responsibility and social conscience of all citizens, as well as the necessary training so that people can make decisions that favor the quality of life and sustainable development.

Regarding the generation of HW and their management system at the FEVG, it can be concluded that the HWs are generated due to a normal activity of the Faculty as a teaching and research center, and that they do not correspond to a squander of resources or lack of awareness of the users. Nevertheless, as described in this work, some deficiencies have been warned that negatively affect the final management of HWs. Some of these negative aspects have already been corrected, but even though there is still much effort to carry in the direction of reducing the amount of HW and the costs related to their management, with this work and the cooperation of all the personal from the FEVG, achieving the objectives will be much easier.

\section{Acknowledgements}

This work was financed by the Campus Biz̨ia Lab program (19ROJO).

\section{References}

Augustsson, A., Sörme, L., Karlsson, A., \& Amneklev, J. (2017). Persistent hazardous waste and the quest toward a circular economy: The example of arsenic in chromated copper Arsenate-Treated wood. Journal of Industrial Ecology, 21(3), 689-699. doi:10.1111/jiec.12516

Brusseau, M. L., Pepper, I. L., \& Gerba, C. P. (2019). Environmental and pollution science (Third edition ed.). London: Elsevier, AP, Academic Press.

Carballo-Penela, A., \& Castromán-Diz, J. L. (2015). Environmental policies for sustainable development: An analysis of the drivers of proactive environmental strategies in the service sector. Business Strategy and the Environment, 24(8), 802-818. doi:10.1002/bse.1847

Cousins, I. T., Ng, C. A., Wang, Z., \& Scheringer, M. (2019). Why is high persistence alone a major cause of concern? Environmental Science: Processes \& Impacts, 21(5), 781-792. doi:10.1039/C8EM00515J

Dirección de sostenibilidad. (2018). Minimización deresiduos químicos. manual de buenas prácticas. Leioa: Servicio Editorial de la Universidad del País Vasco.

European Union. Decision 2000/532/EC: Commission Decision of 3 May 2000 replacing Decision 94/3/EC establishing a list of wastes pursuant to Article 1(a) of Council Directive75/442/EEC on waste and Council Decision 94/904/EC establishing a list of hazardous waste pursuant to Article 1(4) of Council Directive 91/689/EEC on hazardous waste. Official Journal of the European Union L 226, 06 June 2000, 3-24.

European Union. Decision 2014/955/EU: Commission Decision of 18 December 2014 amending Decision 2000/532/EC on the list of waste pursuant to Directive 2008/98/EC of the European Parliament and of the Council. Official Journal of the European Union L 370, 30 December 2014, 44-86.

European Union. Directive 2008/98/EC of the European Parliament and of the Council of 19 November 2008 on waste and repealing certain Directives. Official Journal of the European Union L 312, 22 Novembre 2008, 3-30.

European Union. Directive 2019/130/EC of the European Parliament and of the Council of 16 January 2019 amending Directive 2004/37/EC on the protection of workers from the risks related to exposure to carcinogens or mutagens at work. Official Journal of the European Union L 30, 31 January 2019, $112-120$.

European Union. Regulation 440/2008 of 30 May 2008 laying down test methods pursuant to Regulation (EC) No 1907/2006 of the European Parliament and of the Council on the Registration, Evaluation, 
Authorisation and Restriction of Chemicals (REACH). Official Journal of the European Union L 142, 31 December 2008, 1-39.

European Union. Regulation 1272/2008 of the European Parliament and of the Council of 16 December 2008 on classification, labelling and packaging of substances and mixtures, amending and repealing Directives 67/548/EEC and 1999/45/EC, and amending Regulation (EC) No 1907/2006. Official Journal of the European Union L 353, 31 December 2008, 1-1355.

Ferronato, N., \& Torretta, V. (2019). Waste mismanagement in developing countries: A review of global issues. International Journal of Environmental Research and Public Health, 16(6), 1060. doi:10.3390/ijerph16061060

Huang, M., \& Rust, R. T. (2011). Sustainability and consumption. Journal of the Academy of Marketing Science, 39(1), 40-54. doi:10.1007/s11747-010-0193-6

Kallen, S. A. (2017). Trashing the planet. Minneapolis: Lerner Publishing Group.

Leal Filho, W., Shiel, C., Paço, A., Mifsud, M., Ávila, L. V., Brandli, L. L., . . Caeiro, S. (2019). Sustainable development goals and sustainability teaching at universities: Falling behind or getting ahead of the pack? Journal of Cleaner Production, 232, 285-294. doi:10.1016/j.jclepro.2019.05.309

O'Flaherty, J., \& Liddy, M. (2018). The impact of development education and education for sustainable development interventions: A synthesis of the research. Environmental Education Research, 24(7), 10311049. doi:10.1080/13504622.2017.1392484

United Nations Division for Sustainable Development. (2015). Transforming our world: The 2030 agenda for sustainable development United Nations Division for Sustainable Development.

United Nations. Economic and Social Council. (2019). Special edition: Progress towards the sustainable development goals. O.United Nations Division for Sustainable Development.

Universidad del País Vasco, UPV/EHU. (2019). EHUagenda 2030 for sustainable development. Leioa: Servicio Editorial de la Universidad del País Vasco.

Zamora-Polo, F., \& Sánchez-Martín, J. (2019). Teaching for a better world. sustainability and sustainable development goals in the construction of a change-maker university. Sustainability, 11(15), 4224. doi:10.3390/su11154224 